\title{
Water Governs the Climate on the Earth After the Sun
}

\author{
Alain Toureille \\ Electronic Institute of Systems, Department of Energy, University of Montpellier, Montpellier, France \\ Email address: \\ toureille.alain@orange.fr
}

To cite this article:

Alain Toureille. Water Governs the Climate on the Earth After the Sun. International Journal of Energy and Environmental Science. Vol. 6, No. 5, 2021, pp. 128-133. doi: 10.11648/j.ijees.20210605.13

Received: August 23, 2021; Accepted: September 9, 2021; Published: October 5, 2021

\begin{abstract}
Today, the Earth Global Warming is evocated everywhere. This very important phenomenon should be due to a «greenhouse» effect. Water and Carbon Dioxide are the principal greenhouse gas. But the last reports (2010-2020) of GIEC (International Group for the Evolution of Climate) or IPCC (Intergovernmental Panel on Climate Change) are claiming that the increase of carbon dioxide during the industrial period (1750-today) from $300 \mathrm{ppm}$ to 410 ppm is the principal actor of the Global Warming. The reasons evocated by the GIEC are: on our planet, the water quantity is stable and its cycle is very short (one week) but the life time of carbon dioxide is long (one century) and it is still increasing. In last reports about the climate, water disappears from greenhouse gas list! In this paper, we show that in fact water -and not the $\mathrm{CO}_{2}$ - is responsible for the global warming on Earth. To prove this assertion, first, we'll analyze the total absorption electromagnetic spectra of $\mathrm{H}_{2} \mathrm{O}$ and $\mathrm{CO}_{2}$ (from 0.6 micron to very far infrared). We'll calculate the energetic ratio between $\mathrm{H}_{2} \mathrm{O}$ and $\mathrm{CO}_{2}$ to warm the Earth. It is between 20 and 200 according the regions in favor of $\mathrm{H}_{2} \mathrm{O}$. Then, we'll consider all waters (oceans, vapor, clouds, rains, watering, anthropic origin...) to conclude that water -after the sun- determines the climate on the Earth.
\end{abstract}

Keywords: Water Dipole, Global Warming, Greenhouse, Electromagnetic Absorption, Climate

\section{Introduction}

Following IPCC (Intergovernmental Panel on Climate Change), the greenhouse effect is explained here: the Earth surface is warmed with the short waves (around 0.5 micron) given by the sun (with some reflections), then the warm surface reemits this energy with long waves (Infrared around 10-15 microns).

The greenhouse gases, above the Earth, absorb and then reemit these infrared waves increasing the warming of the Earth atmosphere [1].

Today the global warming of the Earth is recognised everywhere: Figure 1 given by Our World in Data shows the mean temperature on the Earth for 1860 to 2019. The different reports of GIEC (International Group for the Evolution of Climate) and IPCC give an increase of the mean temperature about $0.8^{\circ} \mathrm{C}$ in 2019 and forecast an increase of several degrees in the future (2050). These groups explain that the carbon dioxide is the principal actor concerning this increase because its concentration has clearly been evaluated (from $300 \mathrm{ppm}$ to $410 \mathrm{ppm}$ ) during the last centuries when the industrial activity has been developed very strongly (from
1750 to 2020). However, these groups say that the greenhouse effect is due to $\mathrm{H}_{2} \mathrm{O}$ (but constant), and $\mathrm{CO}_{2}$, (but increasing) [2]. So, $\mathrm{CO}_{2}$ is the principal cause of the global warming. In fact these groups assert the concentration in water is stable and the water cycle is very short (one week) while the $\mathrm{CO}_{2}$ which is the main anthropic gas has with a 100 years long cycle [1].

These assertions are not exact. First, water vapor is the principal greenhouse gas in atmosphere due to its concentration between $0.4 \%$ to $4 \%$ and its very large electromagnetic spectrum contains more 12000 sites. Then $\mathrm{CO}_{2}$ concentration is only $0.04 \%$ and its electromagnetic spectrum is limited to some sites.

Moreover, water vapor is also an anthropic gas: we have produced at the same time water and carbon dioxide in thermic systems: we have added vapor due to enormous watering since $1960 \ldots$ At last, the oceans contain an enormous quantity of water and play an important role on the climate of our planet [2].

Therefore, to be clear, first, we'll analyse in details the electromagnetic spectra of water and carbon dioxide and we make calculations to quantify the effects of the water on the climate considering the entire water on the Earth.

We discuss numerically about the quantities of $\mathrm{CO}_{2}$ and $\mathrm{H}_{2} \mathrm{O}$ produced and their effects. In this discussion we mention the 
models and applications concerning the clouds with their results.

Then, we consider also the energy of the ocean.
Finally, we conclude that the water governs the climate on the Earth after the Sun.

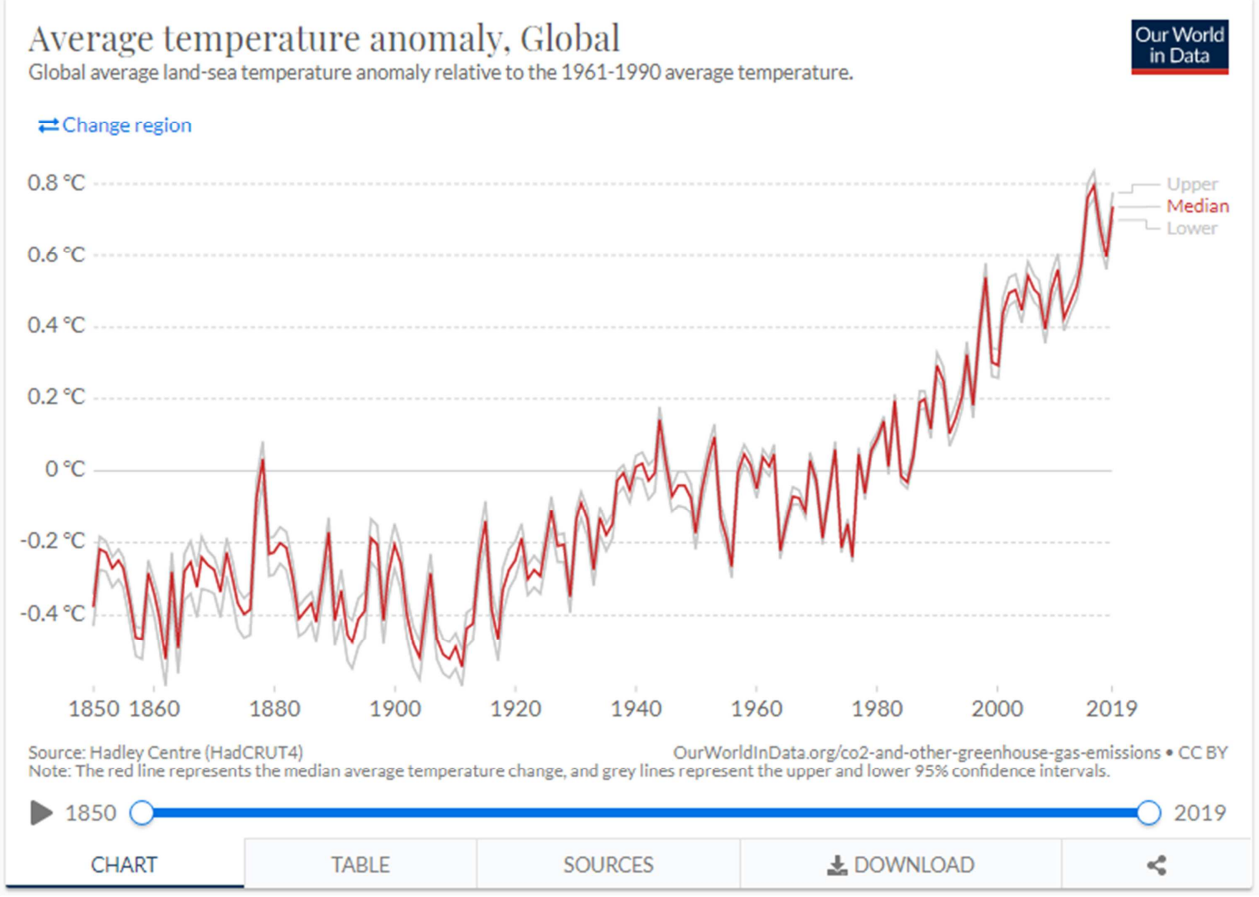

Figure 1. Average temperature anomaly, Global Warming given by Our World in Data.

\section{2. $\mathrm{H}_{2} \mathrm{O}$ and $\mathrm{CO}_{2}$ Spectra}

The water molecule is a strong dipole with the value 1.84 Debye: the distance O-H is $0.9564 \AA$ and the angle between the two $\mathrm{O}-\mathrm{H}$ is $104^{\circ} .45$, we have calculated the equivalent positive charge on each $\mathrm{H}$, it represents 0.527 of elementary charge (two equivalent negative charges on $\mathrm{O}$ ). Due to this very particular structure this light molecule contains a very great number of modes of symmetric, asymmetric and bent vibrations in electromagnetic spectrum. It has a very small moment of inertia on rotation which permits this molecule to reach combined vibrational and rotational spectra containing tens of thousands of absorption lines.
Calculations give theoretically [3-5] 20 modes of vibrations corresponding to wavelengths from 0.6 micron to 10 microns and so 32 modes of rotations corresponding to wavelengths from 10 microns to 500 microns. In fact, it appears in our atmosphere experimentally 10 absorption bands in visible and large bands from 1.0 microns to infrared. The Figure 2, et Figure 3 are given by HITRAN and NASA with $0.4 \%$ of water vapor and 400ppm of $\mathrm{CO}_{2}$. We can see absorptions band from 0.35 micron to 30 microns water vapor absorbs in short waves (the clouds are grey and sometimes almost black!) and also in infrared and far infrared to very long waves giving 12248 sites up to $2 \mathrm{Ghz}$ (see micro waves ovens at $2.45 \mathrm{Ghz}$ ) [6].

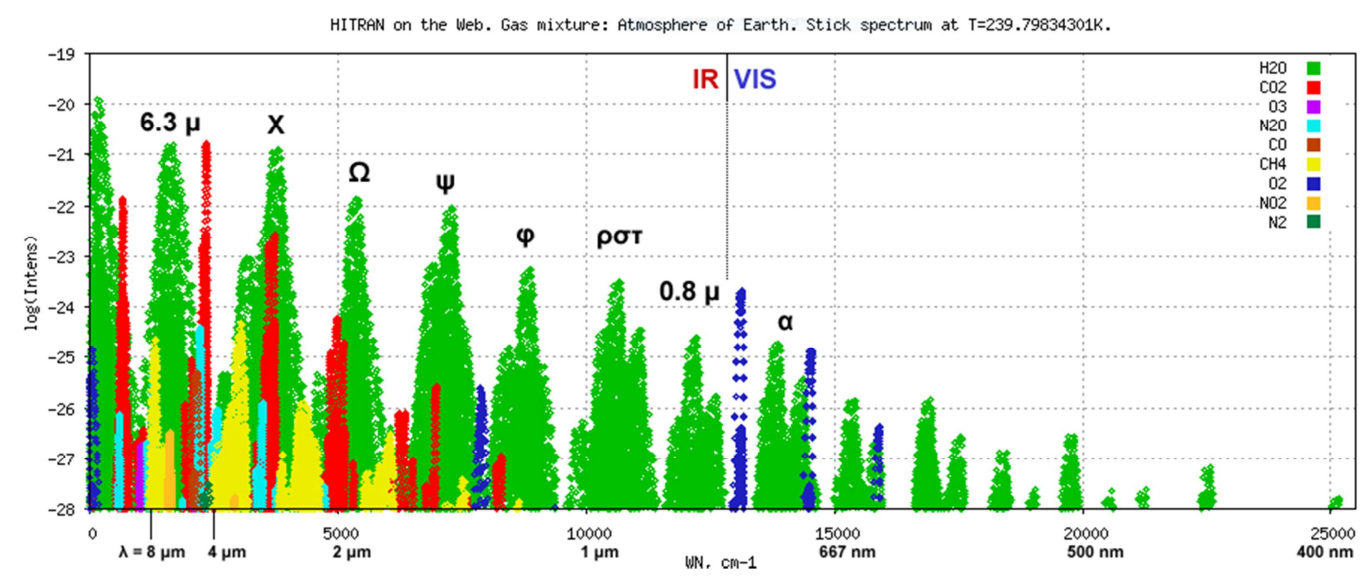

Figure 2. Electromagnetic Absorptions of atmosphere gas after HITRAN (C C). 


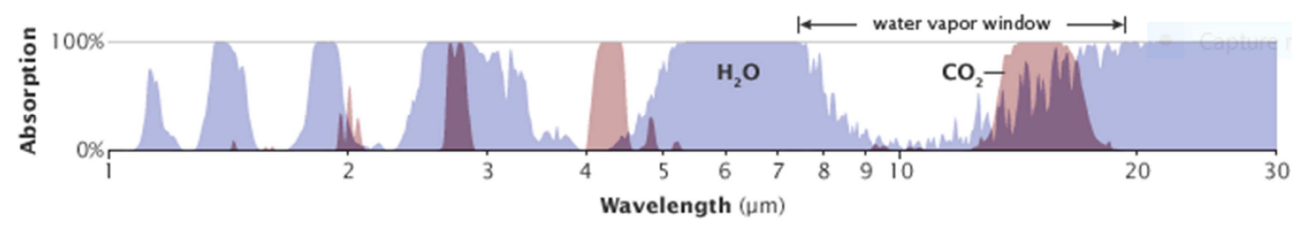

Figure 3. Electromagnetic absorption after NASA showing the overlap at 2, 3, 15 micron, $\mathrm{H}_{2} \mathrm{O}$ in blue, $\mathrm{CO}_{2}$ in grey.

On the contrary, on Figures 2 and $3, \mathrm{CO}_{2}$ which is not a light polar molecule has essentially 5 absorption bands in infrared (IR): 1.80 micron, 2.0 microns, 2.5 microns, 4.3 microns, 15 microns [4]. Only 4 micron band is not screened and over lapped by water vapor (Figure 3 ) given by NASA.

\section{Comparison of Spectra}

On Figures 2 and 3, we see a very great energy is taken by the water alone directly from the sun in the air.

So, during the sunny day, it appears that the sun activates the water essentially in our atmosphere.

From data [3-6] in taking account of different screenings and over lapping it is easy to calculate in considering the total absorption areas that the energetic effect ratio between water vapor and $\mathrm{CO}_{2}$ is at least 20 for one concentration of water vapor of $0.4 \%$. In fact, this concentration can increase to $4 \%$ in hot regions. Taking into account this concentration variation, we deduce that the total energy ratio between water and carbon dioxide for the atmosphere is between 20 (dry air) and 200 (strong screening of water vapor due to humid air).

IPCC considers that the global warming is due to the 15 micron band of $\mathrm{CO}_{2}$. In fact, this band is over lapped by $\mathrm{H}_{2} \mathrm{O}$ absorption 10-15 micron and therefore screened (Figure 3).

IPCC does not give value to this effect about water pretexting that the concentration of the vapor is varies to much in different regions but remains stable on total Earth! Their reference is $\mathrm{CO}_{2}$ with a ratio of 1 compared to others gases only $\left(\mathrm{CH}_{4}, \mathrm{O}_{3}, \mathrm{NO} \ldots\right)$ [1].

Then, another interesting aspect of the heat absorption by the humid air is the variation of the specific heat with the water concentration. Dry air has a specific heat of $1.0 \mathrm{~kJ} / \mathrm{kgK}$. Strong humid air (ratio 0.001 in weight) reaches $3.0 \mathrm{~kJ} / \mathrm{kgK}$ ! The specific heat of carbon dioxide is only $0.6 \mathrm{~kJ} / \mathrm{kgK}$ and has a little action on air as we said previously [7]. We see here the importance of tropic countries (humid air) to heat the Earth.

\section{Liquid Water and Ice Effects}

The particular structure of the water molecule induces other important effects on the climate.

This particularity is due the O-H link between two molecules: it is a hydrogen bond. First example: the density of water is maximum at $4{ }^{\circ} \mathrm{C}$ due to the $\mathrm{O}-\mathrm{H}$ bond which has an optimal configuration at this temperature: this effect allows life in deep water.

In fact, in the liquid a cluster of several molecules is formed and brings new vibration modes increasing the absorption [7-9]. Moreover, this hydrogen bond has an energy of boiling of $2264 \mathrm{~kJ} / \mathrm{kg}$, and a heat capacity (the strongest specific heat of liquids) of $4185 \mathrm{~J} / \mathrm{kgK}$. So these important energies allow a great absorption in oceans coming from the sun. The oceans cover more than $72 \%$ of the planet surface and their depth can reach several kilometres. So, they accumulate an important quantity of heat (1000 times more than the atmosphere!). The evaluations are about several hundred zeta Joule: 10 times the energy consumed by humanity per year!

Therefore, it is concluded that first the sun warms directly the Earth by the water giving an enormous accumulation of heat which governs the climate regulation for our planet.

But water can also provoke many disasters.

When the temperature of water reaches about $28^{\circ} \mathrm{C}$, it appears the possibility to form the hurricanes during a long time with the vapor which is absorbing and then recovering still more energy by raining (condensation). Then this hurricane grows up and continues to grow up to the lands where the source of water disappears (end of run away!).

The clouds (other water form) absorb the sun energy and create a temporary local cooling on the Earth.

In fact, when the evaporation is strong the creating of clouds limits the solar energy: it is the second aspect of climate regulator of water.

Concerning the ice the structure is like a hexagonal crystal (Handbook of Chemistry and Physics). The weak melting energy is $334 \mathrm{~J} / \mathrm{g}$.

The ice is a good thermal insulating and protects the deep water from freezing.

When the pressure increases by accumulation of ice, this weak link breaks and the glaciers bases are melting in iceberg and fall down.

\section{Numeral Discussion}

We have seen that the water has the fundamental role on the climate on our planet (particular structure numerous sites of absorptions and great quantity in ocean).

For the GIEC the greenhouse effect due to the water vapor is recognised as important (50-60\% only!) but stable because the cycle of water is short (one week) while the cycle of carbon oxide is long (one century) and its contribution is growing [1].

Then now, here are some numerical values in atmosphere given by Our World in Data: The air mass is $5148000 \mathrm{Gt}$ (1 $\mathrm{Gt}=10^{12} \mathrm{~kg}$ ), The water vapor mass is $12900 \mathrm{Gt}$. The phreatic nappe is about $10000 \mathrm{Gt}$. The total rain fall is about $505000 \mathrm{Gt}$ per year. So, the water vapor in atmosphere has a renewal about 9 days and the phreatic nappe $(10000 \mathrm{Gt})$ has a renewal of 8 days (water cycle). In 1870 the atmosphere contains 300 ppm in volume of $\mathrm{CO}_{2}$ which corresponds to $2349 \mathrm{Gt}, 410$ ppm of $\mathrm{CO}_{2}$ corresponds to $3211 \mathrm{Gt}$, the increase is $862 \mathrm{Gt}$ 
between 1870 -2020. If we use the GIEC data, $1625 \mathrm{Gt}$ of $\mathrm{CO}_{2}$ have been produced since 1870 , to day the half is added in the atmosphere $(862 \mathrm{Gt})$, and the other half is added in oceans and $160 \mathrm{Gt}$ in the lands. But the water vapor has been created at the same time. The chemical reaction with coal, gasoil, petrol and oxygen gives new water in mean half of weight of $\mathrm{CO}_{2}$. If we use the GIEC data, therefore, $812 \mathrm{Gt}$ (half of $1625 \mathrm{Gt}$ of $\mathrm{CO}_{2}$ ) of new water have been produced at the same time. This new water ignored by IPCC is more powerful than new $\mathrm{CO}_{2}$. This new water vapor represents a ratio of $6 \%$ of water vapor in atmosphere. Certainly, a great part was absorbed by plants and forests, but to explain an increasing of mean temperature of 1 degree $\mathrm{C}$ this phenomenon must be considered because the water compared to $\mathrm{CO}_{2}$ has an energic ratio between 20 and 200 ! We know of the famous week end under in the rain cited in Nature and NASA caused by the traffic jam and heat in certain USA cities [10, 11].

Another very important new phenomenon since 1960 is the strong increase of the consummation of fresh water due to the watering for the cultivations (75\%), industry and domestic life (Figure 4 given by Our World in Data). This quantity of fresh water is enormous now: $4200 \mathrm{Gt} /$ year (more $42 \%$ of phreatic layer). The principal users of water (India, USA, China, Australia.) use some rivers which are drained in each country with more than $800 \mathrm{Gt}$ per year of watering. This quantity has been multiplicated by 4 since 1960 as shown in Figure 4! So, the cultivation ratio has been multiplied by 10 and by this way has decreased the $\mathrm{CO}_{2}$ but has also increased locally the vapor of water from 4 to $6 \%$ as shown now by satellite measurements NOAA! [12]

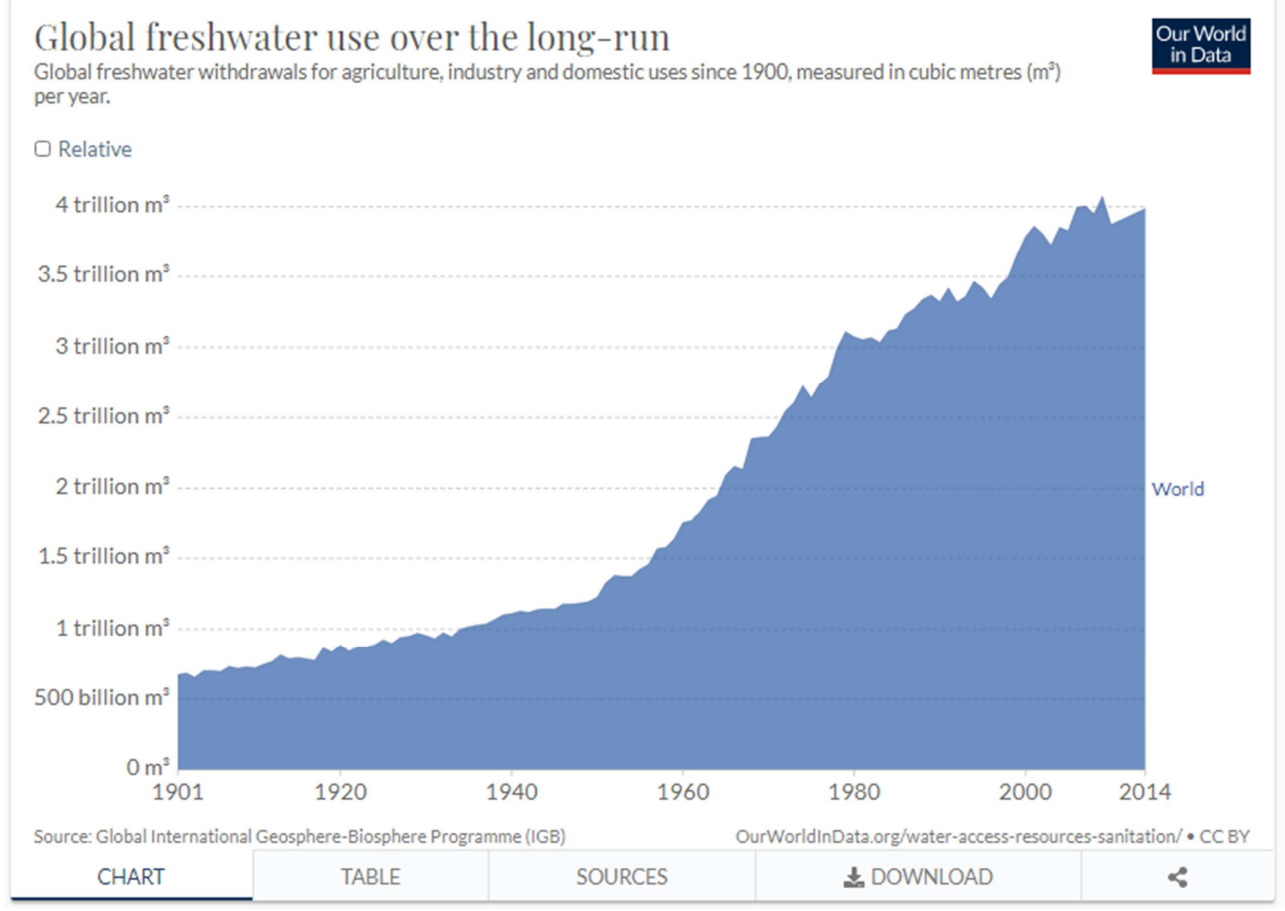

Figure 4. Global fresh water from 1900 to 2014 after Our World in Data.

Then we can see the great similar evolution of Global Warming (Figure 1) and the consummation of fresh water (Figure 4)!

IPCC says: the water cycle is short and all the water goes to ocean. Therefore, the water vapor is constant! It is not true. The water cycle is between 8 and 9 days. So the new water vapor added in atmosphere must be considered during this period. In India for example, the cultivated space is about 70 million of hectares. The ratio with the surface of the Earth is 70000. The atmosphere before this space contains $12900 \mathrm{Gt} / 70000=0.18 \mathrm{Gt}$ of water vapor in normal conditions. During one cycle of water the volume of watering is $800 \mathrm{Gt} / 40=20 \mathrm{Gt}$ ! So with some $\%$ of evaporation in these countries the added water vapor consummed is greater than normal water vapor in atmosphere in one cycle! This effect must have some consequences on the Climate!

For these last 20 years many discussions have concerned the effects of clouds.

High cloud reflects the sun ray and the infrared coming from the earth. The low cloud absorbs the sun ray and the greenhouse infrared coming from the earth. But so, it stops the convection and can reemit infrared to the earth like water vapor. Therefore, the situation is complex concerning all the clouds on earth. The first theoretical models gave a very light cooling due to the clouds [13], but now the last results measured by satellites show that the clouds contribute to the Global Warming [14]. So, new applications are developed to use artificial low clouds by sprays with sea water droplets [15] or aerosols generation on the ocean surface [16]. At last, some authors think that the ionisation due to very high speed particles coming from the sun can be responsible for certain cloud formations [17]. 
We have seen that the oceans play a very important role with one mass of $1.410^{21} \mathrm{~kg}$ (300 times atmosphere mass). It is the greatest tank of heat of the planet. The sea currents (surface and depth) are now studied and the cycle of water is in fact very long! It is not one week as said by IPCC but in hundred years! [18, 19] The effects of temperature and salinity gradients provoke several sea moves called upwellings and downwelling which act as a convection effect to heat the sea in depth. So certain effects (El Nino, El Nina) begin to be explained, but the study will take a long time (Figure 5).

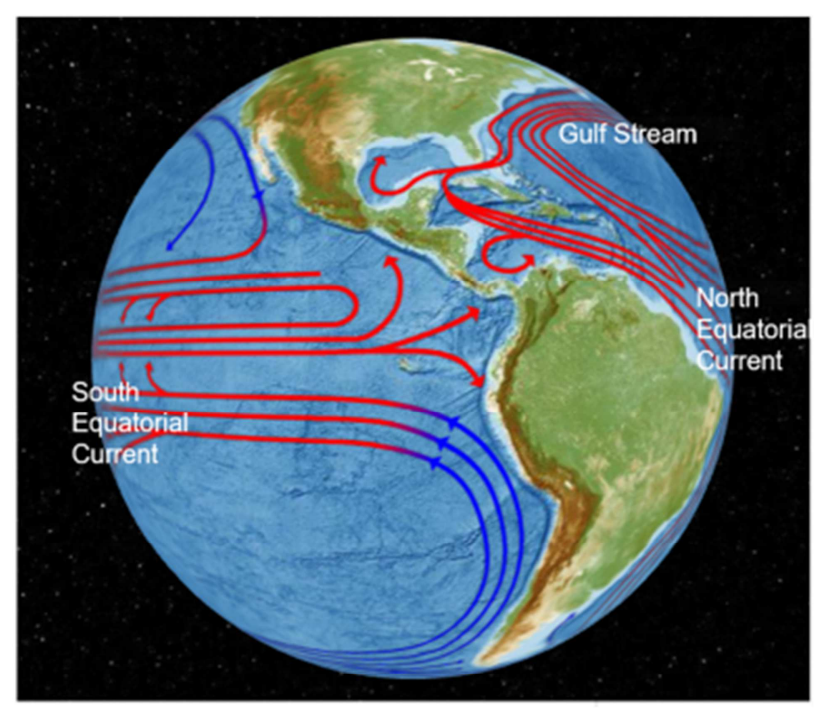

Figure 5. Oceanic Currents (given by National Oceans Service).

The ocean is therefore the second source of heat after the sun. Its accumulation is linked with the greenhouse effect of the water vapor before of its surface.

The climatic phenomena (overflood, hurricanes...) registered today are local and depending on the water concentration in this region.

So, it appears the great complexity of the climate: variation of parameters on the Earth (humidity, clouds.), but so the cycles of the sun $(11,22,60$ years...), incline of Earth axis [20, 21].

\section{Conclusion}

The predictions for the climate in short duration of some ten years are very difficult, because the enormous quantity of water plays a fundamental role by electromagnetic absorption: first direct effect from the sun (visible rays) and then indirect with the greenhouse effect in infrared and far infrared. The climate seems chaotic because many phenomena are active (humidity, clouds, oceanic currents.) and very long to study. But the particularity of the water molecule form (dipole and lightness) governs the climate and allows the life on the planet Earth.

The carbon dioxide does not play the important role given by IPCC and GIEC, the water is the second heat source after the sun and could be responsible of global warming of Earth.
To understand entirely the mechanism of the global warming today, it is necessary to study the great accumulation of heat in the oceans and the exchanges atmosphere-sea-sun.

The great quantity of watering in some countries (USA, China, India, Australia.) could be reduced during some years to see the effects on the Climate on the Earth.

\section{References}

[1] "Climate Change" The IPCC Scientific Assesment, World Meteorological Organisation, Cambridge University Press.

[2] Greenhouse effect more subtle than we believe", Jean-Louis Dufresne and Jacques Treiner, La Metrologie, February 2011.

[3] Laurent Coudert and All "Bending-Rotations Modes", Journal of Molecular Spectroscopy (JMS), 251, (2008), 339-360.

[4] HITRAN data Licence Creative Common.

[5] Bending-Rotations in Water", Rothman and All, Journal of Quantitative Spectroscopy, 110, (2009), 533-5725.

[6] La Nature de l'Eau" Yann Oliveaux Resurgence 2007.

[7] Physique du Climat” J. M. Moranne March 2019 (Web Free Access, C. C.).

[8] Infrared intensities of liquids XX” Bertie J., Lanz Z. Applied Spectroscopy 50, 1047-1057. 
[9] "The hydrogen Bound and the Water Molecule", Elsevier, 2007.

[10] "Weekly cycles of air pollutants, precipitations and tropical cyclones in the coastal NW Atlantic Regions" R. S. Cerveny and Balling, Nature $\mathrm{n}^{\circ}$ 394, 6 august 1998 p 61-563.

[11] "NASA Satellite Confirms Urban Heat Island Increase Rainfall Around the Cities" Goddar Space Center NASA, 18 june 2002.

[12] [19] S. E. Climato logical Atlas of The World Ocean, NOAA, Levitus, Feb 2019.

[13] "Albedo enhancement of marine clouds to counteract Global Warming impact on the hydrological cycles" G. Bala and All, Climate Dynamics (2011) 37: 915-931.

[14] [14] "Observational evidence that cloud feedback amplifies Global Warning", Paulo Ceppi, Peer Nowack Imperial College of London, London United Kingdom.

[15] "Sea-going hardware for the cloud albedo method of reversing Global Warning" Stephen Salter, Graham Sortino, and John Latham, Phil. Trans. R. Soc A (2008) V366, 3989-4006.
[16] "Effect of anthropogenic sulfate on cloud drop nucleation and optical properties" Catherine C. Chung, Joyce E. Penner, Tellus (1995) 47B, pp 281-300.

[17] "The response of clouds and aerosols to cosmic rays decreases" J. Svensmark, M. B. Enghoff, N. J. Shaviv, H. Svensmark, Journal of Geophysics Researches Space Physics, 2016,; DOI; 10.1002/ 2016JA022689.

[18] Atmospheric and Oceanic Sciences Library New York Springer, V. E. Zuev, Retrieved August 4, 2012.

[19] "Infra Red and Raman Specra of Inorganic and Coordination Components" Nakamoto, Kazno, Wiley p 170, 1997.

[20] Cycles de Milankovich, original publication: "Kanon der Erdbestrahlungen und seine Anwendung auf das Eiszeitenproblem, Belgrade, 1941”.

[21] Influence of relative humidity and clouds, on the global mean temperature" J. Kauppinen, J. Heinonen, P. Malmi, Energy and Environment, 25 (2); 389-399, 2014. 